Boletim Técnico do Instituto Agronômico do Estado de São Paulo

Vol. 15

Campinas, abril de 1956

N. 6

\title{
NEMATOIDES QUE PARASITAM A SOJA NA REGIÃO DE BAURU $\left(^{*}\right)$
}

\author{
Itiz Gonzaga b. Lordelio
}

Engenheiro-agrônomo, Escolu superior de Agricultura "Luiz de Queiroz", Cniversidale de São Paulo

\section{RESUMO}

Entre oc sérios fatôres que atuam contra a expansão da cultura da soja no Estado de São Paulo, acha-se o representado por nematóides parasitos. Dêstes, os que mais têm atraido a atenção dos cultivadores e fitopatologistas são as espécies formadoras de galhas no sistema radicular (Meloidogyne spp.).

O estudo do material atacado coligido em Bauru revelou que, naquela região, três formas se acham envolvidas, a saber : Pratylenchus sp., Meloidogyne incognita (Kofoid \& White, 1919) Chitwood, 1949 e $M$. javanica bauruensis n. subsp.

Neste trabalho é estudada a nova subespécie, sendo também apresentadas algumas observaçōes sôbre a população de $M$. incognita.

\section{1 - INTRODUÇÃO}

Silva, Lordello e Miyasaka (3) publicaram algumas observações acêrea da resistência de diversas variedades de soja (Glycine max (L.) Merrill) aos nemat6ides das galhas na região de Campinas. Ainda não foi realizado o estudo detalhado dos nematóides envolvidos nos experimentos feitos, os quais foram considerados como próximos de Meloidogyne incognita (Kofoid \& White, 1919) Chitwood, 1949. Uma das variedades experimentadas, denominada La 41-1219, mostrou-se resistente, constituindo material prometedor para novos estudos e trabalhos de melhoramento. Entretanto, tal variedade, quando plantada na região de Bauru, foi severamente atacada por $M$. incognita, de acôrdo com o material que se teve em mãos. Ataques por M. javanica bauruensis não foram observados nesta variedade, porém sòmente na Abura, cultivada no mesmo campo. Isso nos mostrou que houve forte preferência dos nematóides presentes para cada uma das

(*) Traba lho realizado no Departamento de Agricultura dos Estados Unidos da América do Norte (Section of Nematology Investigations), quando o autor era bolsista da Fundação Rockefeller.

Aos nemat6́logos Dr. G. Steiner e A. L. Taylor o autor agradece o valioso auxflio prestado durante o andamento deste trabalho.

Recebido para publicação em 14 de outubro de 1955. 
variedades em cultivo na mesma parcela. $M$. incognita atacou somente a variedade La 41-1219 e $M$. javanica bauruensis, ùnicamente a variedade Abura (2).

Invasões por Pratylenchus sp. foram verificadas igualmente nas duas variedades envolvidas. Espécies do gênero Pratylenchus Filipjev, 1934, infelizmente, vêm se mostrando bastante abundantes em diversas regiões de S. Paulo, prejudicando o sistema radicular de inúmeros vegetais de importância econômica.

\section{2 - DESCRIÇÃO DE MELOIDOGYNE JAVANICA BAURUENSIS N. SUBSP.}

Ovos - Elipsóides, medindo 90,0-112,5 micros de comprimento e 37,0-52,0 micros de largura (fig. 1, $H$ ).

Larvas ( ${ }^{~}$ ) - Comprimento, 345,3-352,0 micros; largura, 11,6-15,0 micros; estilete, 11,0-11,6 micros; bulbo mediano do esôfago, 13,3-15,0 x 6,6-8,3 micros; $\mathrm{a}=23,5-29,8 ; \mathrm{b}_{1}=6,1-6,5\left({ }^{2}\right) ; \mathrm{c}=$ ?.

As larvas são esguias, afilando-se para as estremidades, principalmente para a posterior, terminando em cauda mais ou menos fina.

Bulbos do estilete pouco desenvolvidos e arredondados (fig. 1, $G$ ). Bulbo mediano do esôfago alongado ou ovóide e algumas vêzes mostrando uma constrição ao nível de sua porção média. Células do intestino invariàvelmente tomadas por substâncias coaguladas, formando corpos no geral arredondados e característicos.

Fasmídeos pequenos; ânus difícil de ser localizado (fig. 1, E). Cutícula finamente estriada no sentido transversal. Os campos laterais, ao meio do corpo, medem 3,3 micros de largura e são formados por quatro riscas paralelas e onduladas, sendo que a ondulação das linhas externas é sensìvelmente mais evidente do que a das medianas. $O$ poro excretor não pôde ser localizado.

Fêmeas - Comprimento, 531,2-846,6 micros; largura, 332,0-531,0 micros; estilete, 15,0-16,6 micros; distância do orificio de abertura do conduto da glândula esofageana dorsal à base do estilete, 3,3-5,0 micros; bulbo mediano do esôfago, 33,2-38,3 x 28,2-33,2 micros; bulbos do estilete, 5,0$5,2 \times 2,0-3,3$ micros; distância da frente da cabeça ao limite inferior do bulbo mediano do esôfago, 78,0-151,0 micros.

As fêmeas maduras são brancacentas e foram, em grande número, obtidas das cavidades presentes no interior dos tecidos. A forma do corpo é globosa e geralmente afilada para a extremidade anterior, resultando um pescoço mais ou menos fino e longo (fig. $1, D$ ); a cabeça, entretanto, é quase sempre arredondada. Estilete curvo, provido de bulbos bem desenvolvidos.

(1) Larvas pré-parasitas ou migrantes.

(2) Relação entre o comprimento total e a distância da frente da cabeça a base do bulbo mediano do esôfago. 

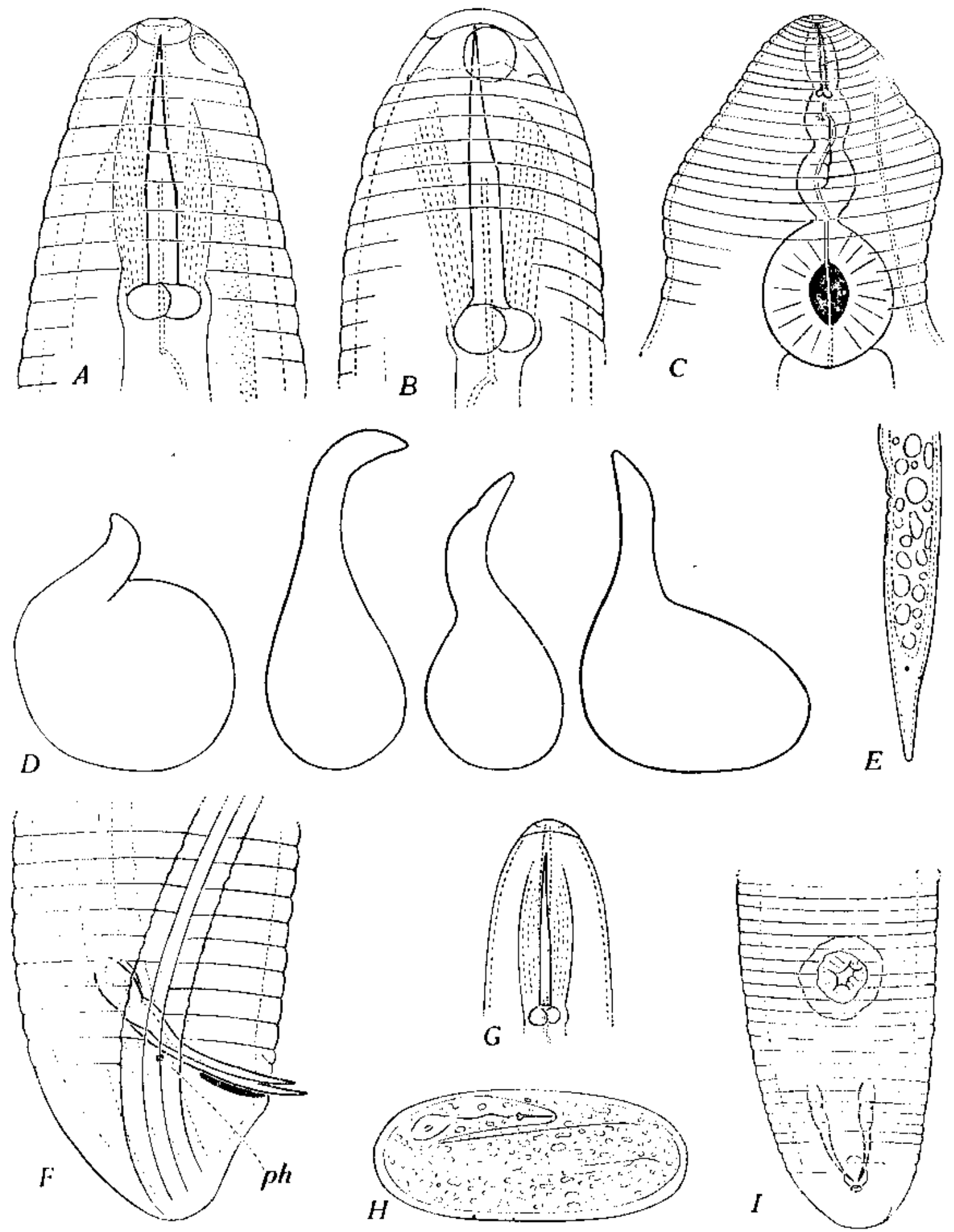

Figlka 1. -- Meloidogyne javanica bauruensis n. subsp. A - cabeça do macho em vista dorso-ventral (x 1730); $B-$ idem, vista lateral (x 1730); $C$ - extremidade anterior da fêmea (x 550);D - forma do corpo de fêmeas maduras (x 50);Eextremidade caudal da larva pré-parasita (x 1000); $F$ - extremidade postcrior do macho, $p h$ - fasmídeo (x 1000); $G$-- cabeça da larva pré-parasita (x 1730); $H$-ôvo cncerrando uma larva (x 550); $I$ - extremidade caudal de macho intersexuado (x 550). 
O canal do esôfago, desde o início do órgão até a entrada para o bulbo mediano, apresenta paredes bem desenvolvidas; depois dêsse ponto, perde-se bastante a sua visibilidade, tornando-se sensivelmente enfraquecidas. Os tecidos que envolvem o canal do esôfago usualmente mostram algumas constrições, das quais a mais profunda localiza-se no ponto de união com o bulbo mediano. Fste bulbo ó quase esférico e bastante desenvolvido (fig. $1, C$ ).

Cutícula fortemente estriada transversalmente. Campos laterais, tal como se vê na ilustração, bastante curtos. No geral êles compreendem um têrço da distância entre a frente da cabeça e o limite superior do bul-

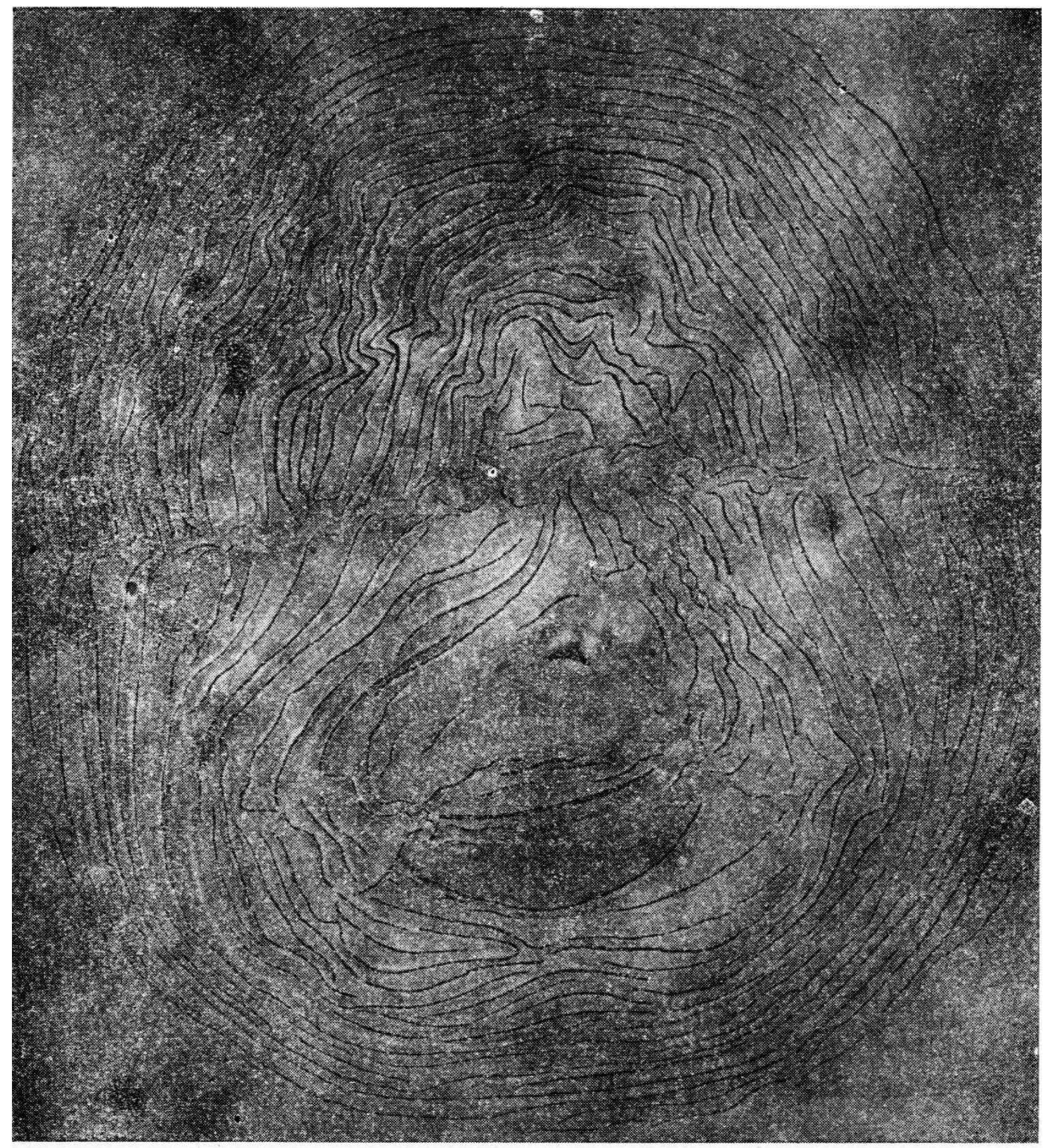

Figura 2. - Configuração perineal de Meloidogyne javanica bauruensis n. subsp. 
bo do esôfago. Antes de atingirem o campo lateral, as estrias transversais inclinam-se levemente para a porção posterior do corpo (fig. $1, C$ ).

A altura do orifício de abertura da glândula dorsal pode ser vista, em bons exemplares, uma estrutura que, por certo, se relaciona com a conexão daquele orifício com o conduto glandular. Poro excretor bem definido e

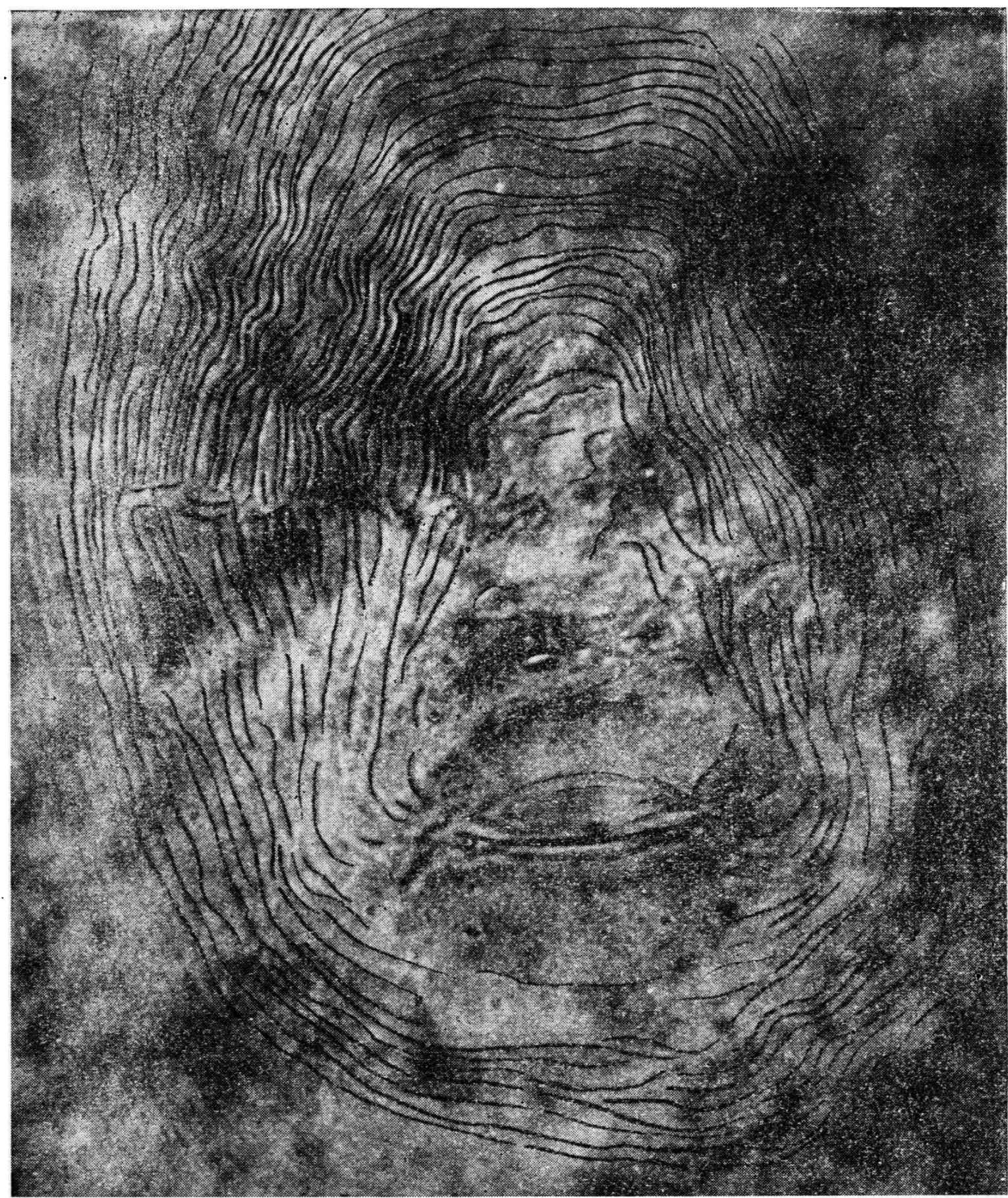

Figura 3. -- Configuração perineal de Meloidogyne javanica bauruensis n. subsp. localizado do $12 .^{\circ}$ ao $18 .^{\circ}$ anel, a contar da cabeça. O conduto excretor pode ser seguido por uma distâneia considerável através do eorpo. 
De acôrdo com a nomenclatura introduzida por Taylor, Dropkin \& Martin (5), a configuração da região perineal de $M$. javanica bauruensis pode ser descrita como a seguir. Linhas laterais dadas por duas incisuras, freqüentemente descontínuas e pouco evidentes, cortando as estrias ou marcadas sòmente por interrupções das estrias ou, ainda, ùnicamente por irregularidades destas. Nos dois primeiros casos, algumas estrias sempre se estendem de um setor a outro, sem serem interrompidas. Arcos e linhas distintos podem ser vistos na região da ponta da cauda. Arcos nítidos também podem ser observados na área central, onde se localizam a vulva e o ânus. As estrias no setor ventral são no geral lisas, das quais as mais interiores se apresentam convexas no lado dorsal. Setor dorsal com arco alto, cujas estrias se apresentam onduladas ou formando zigue-zagues (figs. 2-3). A cutícula, especialmente nos arredores da região perineal, deixa ver pequenos corpos arredondados e dispostos com certa regularidade, os quais foram considerados como núcleos das células cuticulares.

Machos - Comprimento, 968,7-1705,0 micros; largura, 36,5-56,4 micros; estilete, 20,0-23,2 micros; distância do orifício de abertura da glândula esofageana dorsal à base do estilete, 3,3-4,2 micros; bulbos do estilete, 5,0-8,3 × 3,3 micros; bulbo do esoffago, 20,0-21,5 x 13,2-15,0 micros; cauda, 14,0-16,6 micros; espículas, 28,0-33,2 micros $\left({ }^{3}\right)$; altura da cabeça, 4,5-8,3 micros; largura da cabeça, 10,7-15,0 micros; $a=22,1-33,7 ; b_{1}=12,8-$ 13,$5 ; \mathrm{c}=65,0-81,7$.

Os machos são delgados e afilados mais intensamente para a extremidade anterior. A cabeça separa-se do resto do corpo por leve depressão e deixa ver um único anel pós-labial. $O$ anel labial apresenta-se um tanto achatado em vistas laterais (fig. 1, $A-B$ ).

Estilete forte e levemente curvo, com bulbos bastante desenvolvidos. $O$ canal do esôfago, tal como foi descrito para as fêmeas, mostra paredes fortes desde o início do órgão até a entrada para as válvulas do bulbo mediano; daí para diante as paredes perdem muito em visibilidade. $O$ bulbo mediano é mais ou menos oval e, algumas vêzes, deprimido levemente ao nível de seu têrço basal.

Cutícula fortemente estriada, de dois a quatro anéis compreendendo uma distância de 8,3 micros. Os campos laterais estendem-se do nivel do estilete ao extremo caudal, sendo constituidos de quatro incisuras paralelas, das quais as exteriores são bastante onduladas. As riscas medianas são no geral lisas e o espaço que elas compreendem não é percorrido pelas estrias transversais, tal como a ilustração (fig. 1, $F$ ). Um ponto distinto é visto no cruzamento de cada estria transversal com a incisura externa do campo. Assim, duas séries de pontos podem ser vistas ao longo de cada face lateral do corpo, quando se procura seguir as linhas externas dos campos. Ao nível do bulbo esofágico, os campos laterais medem 5,0-6,6 micros de largura e tornam-se gradualmente mais largos, medindo, no meio do corpo, 6,6-13,3 micros. Em certos exemplares podem ser verificadas incisuras adicionais, invariàvelmente muito menos evidentes do que as normais.

(3) As espiculas foram medidas sôbre as cordas dos aeus aroos. 
Com relação ao contorcionamento do corpo dos machos, foi possivel verificar, em um único indivíduo, que está ao redor de 90 graus.

Um ou dois testículos foram observados, os quais podem se apresentar reflexos ou completamente distendidos e, às vêzes, duplamente reflexos, especialmente quando um único testículo é presente. Nos exemplares medidos os testículos estenderam-se pelo corpo de 340,0 a 645,0 micros, a contar do extremo posterior. As espículas apresentam-se arqueadas ventralmente e o gubernáculo é bem desenvolvido. Fasmídeos relativamente grandes (fig. $1, F$ ).

Intersexos - $\mathrm{Na}$ população estudada verificou-se a presença de alguns indivíduos intersexos, de acôrdo com a denominação que, segundo Steiner (4), foi introduzida por Goldschmidt; são indivíduos que possuem, em proporções variáveis, os caracteres dos dois sexos. Entre os nematóides tais ocorrèncias são conhecidas desde muitos anos sob os nomes de hermafroditismo e ginandromorfismo, ambos inadequados. $\mathrm{O}$ têrmo intersexo, porém, é atualmente mais usado para designar tais aberrações.

Steiner, em 1923, descreveu curiosos casos de ocorrência do fenômeno em espécies da família Mermithidae, fazendo referências a diversos outros registrados na literatura (4). Os espécimes descritos por êste autor, mais aquêles conhecidos da literatura, permitem construir uma série completa de fêmeas intersexuadas, que vai da fêmea normal até uma completamente masculinizada. Um fato interessante pôsto em evidência por Steiner é que sòmente fêmeas intersexuadas tinham até então sido observadas (4). Trata-se de exemplares com órgãos femininos completos e normalmente desenvolvidos, cujos úteros e ovidutos comumente exibem ovos. Por outro lado, aparecem caracteres francamente masculinos, tais como papilas caudais próprias dos machos, músculos bursais, espículas etc.. Até aquela data, nenhum investigador havia visto um nematóide macho com caracteres femininos. Tal é o que justamente ocorre em Meloidogyne. Fim certas populações de $M$. javanica, os machos normais chegam a ser raros, pois a sua quase totalidade mostra vestígios de órgãos femininos.

Em $M$. javanica bauruensis, a alteração menos pronunciada afeta sòmente a forma do corpo do exemplar. Tal indivíduo possui testículos e espículas normais, mas a forma do corpo foge muito da usual. Trata-se de um indivíduo não esguio, bem mais curto, com a porção posterior do corpo sensivelmente engrossada (fig. $4, A-B$ ). O exame cuidadoso do organismo não permite divisar nada mais. Os campos laterais podem se alargar ao nível da porção engrossada do corpo e adquirir incisuras adicionais, até nove incisuras tendo sido contadas. As quatro riscas normais, contudo, mostram-se sempre mais nítidas do que as extras.

Num passo mais avançado (aliás o mais avançado que foi obtido), o exemplar mostra igualmente espículas e dois testículos bem desenvolvidos e reflexos e, além de apresentar a mesma alteração na forma, deixa. ver vulva e traços de vagina bem visíveis na parte engrossada do corpo. No espécime cuja parte posterior figura neste trabalho, a vulva localiza-se a 60,0 micros a partir do extremo caudal; os testículos estendem-se pelo corpo 
cêrca de 400,0 micros a contar da ponta da cauda e os campos laterais mostram-se normais, distando as riscas externas, entre si, 8,0 micros, ao nível do meio do corpo. Tal como se vê na ilustração, a estriação transversal da cuticula é interrompida pelos bordos da abertura vulvar (fig. $1, I$ ). As mediras do exemplar, em micros, são as seguintes : comprimento, 851,3;
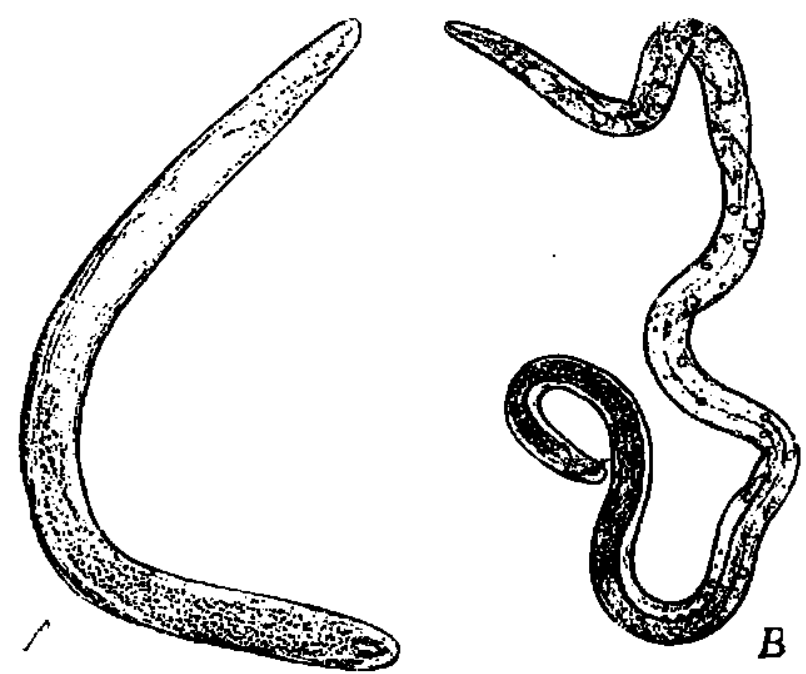

Figura 4. --- Meloidogyne javanir'a bauruensis n. subsp. A - in!ersexo; $B$ - macho normal.

largura, 46,5; cauda, 14,0; espícula, 20,0; distância da abertura do conduto da glândula esofageana dorsal à base do estilete, 1,7; estilete, 20,0; altura da cabeça, 4,2; bulbo do estilete, $6,6 \times 3,3 ; a=18,3 ; b=$ ?; $c=61,3$.

Diagnose - Meloidogyne javanica bauruensis $\mathrm{n}$. subsp. difere da subespécie típica (Meloidogyne javanica javanica (Treub, 1885) Chitwood, 1949), pelos seguintes caracteres : a) ovos geralmente mais largos (37,0$52,5: 31,0-40,0$ micros); b) estilete das larvas pré-parasitas um tanto mais longo (11,0-11,6:10,0 micros); c) pescoço das larvas mais longo $\left.\left(b_{1}=6,1-6,5: b=6,3-8,0\right) ; d\right)$ cabeça dos machos com um único anel pós-labial, a subespécie típica apresentando dois ou três anéis; $e$ ) linhas laterais da configuração perineal menos evidentes do que na subespécie típica e não se estendendo até a região cervical, com estrias prolongando-se, sem serem interrompidas do setor dorsal para o ventral; $f$ ) arco dorsal mais alto, com estrias mais onduladas ou formando zigue-zagues.

Planta hospedeira típica - Soja (Glycine max (L.) Merrill), variedade Abura.

Localidade típica - Bauru, Estado de S. Paulo.

3 -- OBSERVAÇÕES ACERCA DE MELOIDOGYNE INCOGNITA (KOFOID \& WHITE, 1919) CHITWOOD, 1949, VERIFICADA EM ASSOCIAÇÃO COM $M$. JAVANICA BAURUENSIS N. SUBSP.

Ovos - 97,5-105,0 x 37,5 micros.

Larvas - Comprimento, 290,0-300,0 micros; largura, 11,6-13,3 micros; estilete, 10,0-11,6 micros; bulbo mediano do esôfago, 10,0 x 8.3 micros: 
distância entre a frente da cabeça e a base do bulbo do esôfago, 41,5-50,5 micros; $\mathrm{a}=21,8-25,8 ; \mathrm{b}_{\mathrm{l}}=6,0-6,9 ; \mathrm{c}=$ ?.

Fêmeas - Comprimento, 434,0-620,0 micros; largura, 325,5-542,5 micros; estilete, 15,0 micros; distância entre a abertura da glândula dorsal e a base do estilete, 2,5-5,0 micros; distância entre a frente da cabeça e o limite inferior do bulbo do esôfago, 74,7-101,3 micros; bulbo do esôfago, 33,2-34,8 x 31,5-33,2 micros; bulbos do estilete, 5,0-5,8 x 2,0-3,3 micros.

A configuração perineal é grosseiramente oval, com arco alto e constituido de estrias mais ou menos onduladas; ao longo das linhas laterais, nas unióes das estrias dorsais e ventrais, há certa tendência para a formação de bifurcações.

Machos - Comprimento, 686,3-1507,5 micros; largura, 29,0-41,5 micros; estilete, 20,0-23,3 micros; distância da abertura da glândula esofageana dorsal aos bulbos do estilete, 3,3 micros; bulbos do estilete, 5,0-8.3 x 3,3-5,0 micros; espículas, 26,5-33,2 micros; altura da cabeça, 5,0-5,3 mi$\operatorname{cros} ; \mathrm{a}=18,0-36,5 ; \mathrm{b}=$ ?; $\mathrm{c}=51,6-130,0$.

Alguns machos desta população são bastante curtos, tendo de 690,0 a 900,0 micros de comprimento. A cabeça, em qualquer caso, possui dois ou três anéis póś-labiais; os campos laterais podem mostrar riscas adicionais, até sete riscas tendo sido contadas. As riscas externas dos campos distam 3,3-5,0 micros entre si, à altura do bulbo mediano do esôfago; ao nível do meio do corpo, elas distam $6,6-8,3$ micres.

Fm todos os machos estudados apenas um testículo é presente, o qual pode se apresentar reflexo ou completamente distendido.

A população que tivemos em mãos difere daquela estudada por Chitwood (1) por apresentar larvas pré-parasitas menores e mais delgadas e machos com espículas mais curtas.

Planta hospedeira --.- Soja, variedade La 41-1219.

\section{NEMATODE PARASITES OF SOYBFAN IN THE BAGRU REGION}

\section{SUMMARY}

One of the serious detriments to soybean (Glycine $\max$ (L.) Merr.) cultivation in the State of S. Paulo, Brazil, are root-parasitic nematodes. A study of infected material collected at Bauru, where at least two distinct soybean varieties were cultivated, disclosed that three forms were involved: a meadow nematode (Pralylenchus sp.) and two root-knot nematodes (Meloidogyne incognita (Kofoid \& White, 1919) Chitwood, 1949, and $M$. javanica bauruensis n. subsp.).

Silva, Lordello \& Miyasaka (3) published some observations about the resistance of several soybean varieties to the attacks by root-knot nematodes in Campinas. A detailed study of the nernatodes involved in those experiments, which were considered as related do $M$. incognita, has not yet been made. One of the varieties tested, La 411219 , proved to be resistant, thereby providing promising material for further studies and breeding. Unfortunately, such a variety when planted in Bauru, was severely attacked by a root-knot species, which is identified as $M$. incognita. Attacks by $M$. javanica bauruensis was not noted in that variety but was noted in another variety (Abura) growing adjacent in the same field. The host preference of those two nema- 
todes was specific and very marked. $M$. incognita attacked only var. La 41-1219 and $M$. javanica bauruensis only var. Abura. Invasions by meadow-nematodes were equally observed in the two varieties concerned.

In this paper, the study of $M$. javanica bauruensis $\mathrm{n}$. subsp. is made with all the details possible. It differs from the typical subspecies ( $M$. javanica javanica (Treub, 1885) Chitwood, 1949), in having : a) eggs usually wider (37.0-52.5 : 31.0-40.0 micra); $b$ ) stylet of larvae somewhat longer (11.0-11.6:10.0 micra); c) neck of larvae longer $\left.\left(b_{1}=6.1-6.5: b=6.3-8.0\right) ; d\right)$ head of male with a single post-labial annule instead of the two or three present in the typical subspecies; $e$ ) lateral lines in the perineal pattern less evident and not extending to cervical region, with some striae extending unbroken from dorsal to ventral sectors; and, $f$ ) higher arch in the perineal pattern, composed of marked wavy to zig-zag striae.

In the population studied, several males were found for which the term intersex is applied. The less evident alteration that was seen affects only the shape of the male body, which is considerably thicker in its posterior portion and visibly shorter in its total length. The lateral fields are wider at the latitude of the thick portion, where additional incisures can be counted. In the most advanced case of intersexuality observed besides the same alteration in the shape of the body, there is a vulva and traces of a vagina very well defined.

Some data about the $M$. incognita population obtained in association with $M . j a-$ vanica bauruensis are also presented. Such a population only differed from that studied by Chitwood (1) in having shorter and more slender larvae and males with shorter spicules. Very short males were also observed their total length lying between 690 and 900 micra.

\section{LITERATURA CITADA}

1. CHITWOOD, B. G. "Root-knot nematodes". I. A revision of the genus Meloidogyne Goeldi, 1887. Proc. helm. Soc. Wash. 16:90-104. 1949.

2. LORDELLO, L. G. E. Nematodes attacking soybean in Brazil. Plant Dis. Rep. 39:310-311. 1955 .

3. SILVA, J. GOMES DA, LORDELLO, L. G. E. \& MIYASAKA, S. Observações sôbre a resistência de algumas variedades de soja ao nematóide das galhas. Bragantia 12:[59]-63. 1952.

4. STEINER, G. Intersexes in nematodes. J. Hered. 14:147-158. 1923.

5. TAYLOR, A. L., DROPKIN, V. H. \& MARTIN, G. C. Perineal patterns of root-knot nematodes. Phytopathology 45:26-34. 1955. 